Ciência Florestal, Santa Maria, v. 22, n. 4, p. 681-692, out.-dez., 2012

ISSN 0103-9954

\title{
COMPORTAMENTO FISIOLÓGICO DE SEMENTES DE Myracrodruon urundeuva Fr. All. (ANACARDIACEAE) SUBMETIDAS A FATORES ABIÓTICOS
}

\author{
PHYSIOLOGIC BEHAVIOR OF Myracrodruon urundeuva (ANACARDIACEAE) Fr. All. \\ SEEDS SUBMITTED TO ABIOTIC FACTORS
}

\author{
Ivana Oliveira Virgens ${ }^{1}$ Renato Delmondez de Castro ${ }^{2}$ \\ Luzimar Gonzaga Fernandez ${ }^{3}$ Claudinéia Regina Pelacani ${ }^{4}$
}

\begin{abstract}
RESUMO
O objetivo deste trabalho foi avaliar o comportamento germinativo de sementes de Myracrodruon urundeuva sob diferentes temperaturas e potenciais hídricos, a combinação destes, assim como a viabilidade das sementes após condicionamento osmótico. Os ensaios foram conduzidos em delineamento inteiramente casualizado, com quatro repetições de 50 sementes/tratamento. Foram testadas as temperaturas constantes de $20,25,30,33,35$ e $40{ }^{\circ} \mathrm{C}$, com as sementes embebidas em água destilada. Em outro ensaio, testou-se os potenciais osmóticos de 0,0 (testemunha); $-0,2 ;-0,4 ;-0,6 ;-0,7 ;-0,8 ;-0,9 ;-1,0$ e -1,2 MPa, utilizando-se soluções de PEG (6000). A partir desses ensaios estabeleceram-se as temperaturas e os potenciais osmóticos de máxima germinação (temperatura e potencial ótimo), o de $50 \%$ e a de germinabilidade nula. Ao final do ensaio de screening hídrico foi realizada uma averiguação da capacidade germinativa das sementes não germinadas nos potenciais osmótico onde a germinabilidade foi nula. Também foram combinados diferentes temperaturas com diferentes potenciais osmóticos. As sementes de Myracrodruon urundeuva iniciam a germinação em dois dias. Na temperatura de $25{ }^{\circ} \mathrm{C}$ foi obtida a germinação máxima para as sementes da espécie, na de $33{ }^{\circ} \mathrm{C} 50 \%$ das sementes germinaram e na de $40{ }^{\circ} \mathrm{C}$, a germinabilidade foi nula. Com relação à restrição hídrica induzida, $-0,2 \mathrm{MPa}$ foi o potencial ótimo de germinabilidade, $-0,7 \mathrm{MPa} o$ potencial de $50 \%$ de germinação e a partir de - 0,9 Mpa a germinabilidade foi nula. Os potenciais osmóticos de $-0,9 ;-1,0$ e -1,2 MPa, podem ser utilizados para condicionamento osmótico desta espécie. As sementes de Myracrodruon urundeuva não toleram os estresses de altas temperaturas e diminuição dos potenciais osmóticos, concomitantemente, uma vez que reduzem a germinabilidade e o vigor das sementes.
\end{abstract}

Palavras-chave: aroeira-do-sertão; screening térmico; screening hídrico.

\section{ABSTRACT}

The aim of this work was to evaluate germinating seeds of Myracrodruon urundeuva under different temperatures and hydrous potentials, the combination of both and the seeds viability after osmotic conditioning. The assay was conducted in a totally casual analysis with four repetition contained 50 seeds by treatment. The temperatures of $20,25,30,33,35$ and $40{ }^{\circ} \mathrm{C}$ were tested with seeds soaked in distilled water. In another assay, the osmotic potentials of 0,0 (evidence) were tested; $-0,2 ;-0,4 ;-0,6$; $-0,7 ;-0,8 ;-0,9 ;-1,0$ e $-1,2 \mathrm{MPa}$ using PEG 6000 solutions. Based in these tests, it was established the

1. Bióloga, Doutoranda do Programa de Pós graduação em Processos Interativos dos Órgãos e Sistemas pela Universidade Federal da Bahia, Laboratório de Bioquímica, Biotecnologia e Biocompostos, Instituto de Ciências da Saúde (ICS/UFBA), Av. Reitor Miguel Calmon, s/n, Vale do Canela, CEP 40160-100, Salvador (BA). ivanaovirgens@yahoo.com.br.

2. Engenheiro Agrônomo, Dr., Professor Adjunto da Universidade Federal da Bahia, Laboratório de Bioquímica, Biotecnologia e Biocompostos (ICS/UFBA), Av. Reitor Miguel Calmon, s/n, Vale do Canela, CEP 40160-100, Salvador(BA).renatodel@gmail.com.

3. Bióloga e Química, Dra ${ }^{a}$, Professora Associada do Departamento de Biofunção do Instituto de Ciências da Saúde, Universidade Federal da Bahia, Laboratório de Bioquímica, Biotecnologia e Biocompostos, (ICS/UFBA), Av. Reitor Miguel Calmon, s/n, Vale do Canela, CEP 40160-100, Salvador (BA). luzimargonzaga@gmail.com

4. Bióloga, Dr ${ }^{\mathrm{a}}$, Professora Titular, Laboratório de Germinação, Unidade Experimental Horto Florestal da Universidade Estadual de Feira de Santana, Av. Presidente Dutra s/n, CEP 40000-000, Santa Mônica Feira de Santana (BA).pelacani@uefs.br

Recebido para publicação em 03/03/2010 e aceito em 10/08/2011 
best temperatures and the osmotic potentials of maximum germination, fifty percent of germination and no germination. After end of hydrous screening, no germinating seeds in no germinating potentials was tested for its capacity of germinating in water. Also, different temperatures were combined with different osmotic potentials. The seed germination Myracrodruon urundeuva starts in two days. At the temperature of $25^{\circ} \mathrm{C}$, it was obtained for maximum seed germination of the species at $33^{\circ} \mathrm{C}$ for $50 \%$ of the seeds germinated and at $40{ }^{\circ} \mathrm{C}$, the germination was zero. Regarding to water restriction induced $-0.2 \mathrm{MPa}$, it was an optimum germination potential, the potential of $-0.7 \mathrm{MPa} 50 \%$ germination and from $-0.9 \mathrm{MPa}$ and germination was nil. The osmotic potentials of $-0.9,-1.0$ and $-1.2 \mathrm{MPa}$, can be used for priming this species. The seeds of Myracrodruon urundeuva not tolerate the stresses of high temperatures and decreased water potential, concurrently, as they reduce the germination and seed vigor.

Keywords: Aroeira-do-sertão; thermal screening; osmotic screening.

\section{INTRODUÇÃO}

A retomada do crescimento do embrião ou germinação é dependente de muitos fatores externos e internos das sementes, afetando diferentemente esse processo (BASKIN e BASKIN, 1998; RAVEN et al., 2001; BEWLEY e BLACK, 1994). Temperaturas extremas, alta salinidade, excesso ou deficiência hídrica, crostas do solo e presença de insetos e patógenos podem afetar de forma adversa tanto a germinação como o estabelecimento das plantas no campo (VILLELA et al., 1991). Considerando o fator temperatura, de modo geral, a temperatura mínima que possibilita a germinação para muitas espécies apresenta-se entre $0{ }^{\circ} \mathrm{C}$ a $5{ }^{\circ} \mathrm{C}$ e a máxima é de $45^{\circ} \mathrm{C} \mathrm{a} 48{ }^{\circ} \mathrm{C}$, e a faixa ótima está entre $25^{\circ} \mathrm{C}$ e $30^{\circ} \mathrm{C}$. (RAVEN et al., 2001). Hendricks e Taylorson (1976) explicam que altas temperaturas podem causar desnaturação de proteínas e alteração na permeabilidade das membranas, enquanto baixas temperaturas retardam as taxas metabólicas, até o ponto em que as vias essenciais ao início da germinação não podem mais operar.

Com relação à água, esta constitui o fator iniciante da germinação e está envolvida direta e indiretamente em todas as demais etapas do metabolismo germinativo. Sua participação é decisiva nas reações enzimáticas, na solubilização e transporte de metabólitos e como reagente na digestão hidrolítica de tecidos de reserva da semente. $\mathrm{O}$ aumento dos potenciais osmóticos atrasa e diminui a porcentagem de germinação. O grau mínimo de umidade a ser atingido pela semente para que a germinação ocorra depende de sua composição química e da permeabilidade do tegumento (BRADFORD, 1995), caso esta não apresente dormência. No estudo da germinação de sementes, o conhecimento sobre como a deficiência hídrica afeta esse processo tem importância especial na Ecofisiologia, para avaliação dos limites de tolerância e da capacidade de adaptação das espécies (LARCHER, 2000).

Desta forma, as condições térmicas e o potencial hídrico para a germinação de sementes constituem um dos importantes fatores a serem estudados no desenvolvimento das plantas. Em se tratando de espécies ocorrentes em ambientes semiáridos, os mecanismos fisiológicos de sobrevivência à seca têm sido bastante estudados em espécies vegetais cultivadas, no entanto, pouco ainda se sabe sobre o comportamento e os mecanismos de adaptação das espécies nativas às condições de restrição hídrica e altas temperaturas, naturais da Caatinga e Semiárido nordestino.

Em condições de laboratório, foram realizados estudos utilizando soluções aquosas com diferentes potenciais osmóticos para umedecer o substrato de germinação em diferentes níveis de hidratação, promovendo restrição hídrica para a semente (BRADFORD, 1986). O polietilenoglicol $6000\left(\mathrm{HOCH}_{2}\left(\mathrm{CH}_{2} \mathrm{OCH}_{2}\right)_{\mathrm{n}} \mathrm{CH}_{2} \mathrm{OH}\right)$, é um dos agentes osmóticos utilizados nesses estudos, pois é quimicamente inerte e atóxico para as sementes, simulando a seca e não penetrando no tegumento devido ao tamanho de suas moléculas que apresentam alto peso molecular (VILLELA et al., 1991), propiciando assim restrição hídrica às sementes, dependendo da concentração utilizada.

A espécie selecionada para esta pesquisa foi a Myracrodruon urundeuva Fr. All syn. Astronium urundeuva (Fr. All) Engl., conhecida popularmente como aroeira-do-sertão. Trata-se de uma espécie arbórea, nativa da região semiárida do Nordeste brasileiro, de relevante valor socioeconômico, não somente como planta medicinal ou madeireira, mas também, como fonte de energia (lenha) nas indústrias e nas propriedades rurais (MEDEIROS et al., 2000). Diversos trabalhos têm sido conduzidos, 
procurando definir o comportamento fisiológico de sementes de Myracrodruon urundeuva, alguns com vistas à conservação em longo prazo (GONZAGA et al., 2003), outros sob o efeito de estresses na nutrição mineral (SILVA et al., 2000), efeito da luz e da temperatura (SILVA et al., 2002), efeito de temperaturas e substratos (PACHECO et al., 2006), influência da luz na germinação de sementes (MIRANDA et al., 2007), estudos de armazenamento de sementes (CALDEIRA, 2007; LUCIO et al., 2007; SOUZA et al., 2007), estudos de campo (TROVÃO et al., 2004; CARON et al., 2007), entre outros.

Entretanto, apesar de existirem estudos que envolvam o comportamento fisiológico das sementes sob diferentes temperaturas, nenhum dos estudos abordados na literatura buscam avaliar o efeito do estresse hídrico, assim como a combinação de fatores abióticos, a exemplo de térmico $\mathrm{x}$ hídrico, condições nas quais na natureza a espécie está submetida. Sendo assim, o presente estudo prevê investigar estes aspectos, a fim de ampliar os estudos fisiológicos relacionados à espécie em estudo.

\section{MATERIAIS E MÉTODOS}

Os diásporos de aroeira-do-sertão foram coletados de plantas matrizes do Campo Experimental da Caatinga, da Embrapa Semiárido (CPATSA) entre agosto e setembro de 2007, na região de Jutaí, no município de Petrolina PE. Depois de beneficiados, os mesmos foram acondicionados em saco plástico devidamente identificado e armazenado em geladeira, mantidos assim até o início dos testes. Os ensaios foram conduzidos no Laboratório de Germinação da Universidade Estadual de Feira de Santana - UEFS.

Procedeu-se a caracterização inicial do lote realizando-se a pesagem total, peso de 1000 sementes, teste de germinação e o teor de água dos diásporos de acordo com as Regras para Análise de Sementes - RAS (BRASIL, 2009). A determinação do grau de umidade dos diásporos foi calculada com base na massa fresca, obtida em estufa $105 \pm$ $3{ }^{\circ} \mathrm{C}$, por 24 horas, sendo os resultados expressos em porcentagem.

Para todos os ensaios de germinação, inicialmente o exocarpo e mesocarpo dos diásporos foram retirados manualmente em água corrente e as sementes então desinfestadas superficialmente em fungicida derosol $(1 \mathrm{~mL} / 1 \mathrm{~L})$ por um minuto, posteriormente com solução de hipoclorito de sódio
$(\mathrm{NaClO})$ a $5 \%$ durante três minutos e em seguida lavadas com água destilada. As sementes foram dispostas em placas de Petri de vidro $(9 \times 11 \mathrm{~cm})$, contendo ao fundo duas folhas de papel germitest (semiesterilizados em estufa de secagem a $105^{\circ} \mathrm{C}$, por 4 horas) e uma acima, umedecidas com $7 \mathrm{ml} \mathrm{de}$ água destilada ou solução teste e assim mantidas em câmara de germinação ajustada a $25^{\circ} \mathrm{C}$ e fotoperíodo de 12 horas de luz.

Para o screening térmico, foram testadas as temperaturas constantes de $20,25,30,33,35$ e $40{ }^{\circ} \mathrm{C}$ e com as sementes embebidas em água destilada e para o screening hídrico, utilizaram-se soluções de PEG (6000) preparadas nos potenciais osmóticos de 0,0 (testemunha); -0,2; -0,4; -0,6; -0,7; $-0,8 ;-0,9 ;-1,0$ e $-1,2 \mathrm{MPa}$. As soluções osmóticas foram preparadas para a temperatura de $25^{\circ} \mathrm{C}$, a partir da diluição do PEG 6000 em água destilada de acordo com Villela et al. (1991) e metodologia de Michel e Kaufmann (1973). A partir desses ensaios foi possível estabelecer as temperaturas e os potenciais osmóticos de máxima germinação (temperatura e potencial ótimo), o de $50 \%$ e a de germinabilidade nula, onde neste estudo passou-se a designar temperatura e potencial de estresse.

A água e as soluções osmóticas foram trocadas a cada dois dias, a fim de evitar a contaminação do substrato e a manutenção dos tratamentos. As análises foram realizadas em delineamento experimental inteiramente casualizado (DIC), com quatro repetições de 50 sementes por tratamento. Além da porcentagem de sementes germinadas, foi calculado o tempo médio (Tm), a velocidade média $(\mathrm{Vm})$, o índice de velocidade de germinação (IVG) e o coeficiente de uniformidade de germinação (CUG), conforme Santana e Ranal (2004). Os experimentos foram avaliados diariamente. Considerou-se como germinadas as sementes que apresentaram emissão de radícula.

A fim de se avaliar a viabilidade das sementes pós-estresse, ao final do período de avaliação do ensaio de screening hídrico foi realizada uma averiguação da capacidade germinativa das sementes não germinadas nos potenciais osmótico onde a germinabilidade foi nula. Para isso as sementes não germinadas dos tratamentos que mantiveram a mesma quantidade amostral de sementes (200 sementes) foram lavadas com água destilada para retirada do excesso da solução de PEG 6000, transferidas para placas de Petri umedecidas com a mesma quantidade inicial $(7 \mathrm{ml})$ de água destilada e mantidas nas mesmas condições 
de germinação. As sementes permaneceram nessas condições por um período de 10 dias, onde foi contabilizado diariamente o número de sementes germinadas (emissão de radícula) em água após condicionamento osmótico.

A partir dos dados obtidos nos screening térmico e hídrico foi combinada a temperatura de $33{ }^{\circ} \mathrm{C}$ (T50) com diferentes potenciais osmóticos $(0,0 ;-0,2 ;-0,7$ e $-1,0 \mathrm{MPa})$, denominado de experimento 1 e o potencial osmótico $-0,7 \mathrm{MPa}$ ( $\psi 50)$ com as temperaturas: ótima $\left(25^{\circ} \mathrm{C}\right)$, a T50 $\left(33^{\circ} \mathrm{C}\right)$ e a temperatura de germinabilidade nula $\left(40^{\circ} \mathrm{C}\right)$, denominado então de experimento 2 .

Os dados de todas as medidas calculadas foram transformados pela função $(\mathrm{x}+0,5)^{0,5} \mathrm{e}$ submetidos à análise de variância (ANAVA). Para os dados referentes às porcentagens de germinação foram ajustadas equações de regressão polinomial. Todas as análises foram realizadas com auxilio do programa estatístico Sisvar, versão 5.0 (FERREIRA, 2000).

\section{RESULTADOS E DISCUSSÃO}

\section{Caracterização do Lote de Sementes}

As sementes apresentaram germinabilidade inicial de $93 \%$. O peso médio de 1000 diásporos foi de $14,82 \mathrm{~g}$ e o teor de água dos diásporos de $10,17 \%$. Lucio et al. (2007) registraram 9,62\% e Caldeira (2007) verificou 9,7\% no teor de água inicial dos diásporos para a mesma espécie. Valores bem semelhantes aos encontrados neste estudo. Duarte et al. (2000) verificaram, para diferentes lotes de Myracrodruon urundeuva, um peso médio de 13,$08 ; 17,38$ e 17,40 g para 1000 diásporos e teores de água de 9,49; 8,79 e 8,87\%, respectivamente. Os dados encontrados por este autor para um dos lotes avaliados é bem semelhante aos encontrados neste estudo. A diferença de valores encontrados para os outros lotes por Duarte et al. (2000), inclusive com relação ao registrado neste estudo demonstra que é possível haver diferenças entre lotes para estas variáveis, porém, observa-se que o peso das sementes está diretamente ligado ao conteúdo de água apresentado por estas.

Segundo as RAS (BRASIL, 2009), o peso de 1000 sementes é uma informação que dá ideia do tamanho das sementes, assim como de seu estado de maturidade e de sanidade, além de ser uma medida que varia de acordo com o teor de água das sementes, e por estas razões recomenda-se realizar a determinação do grau de umidade para avaliação da qualidade do lote.

\section{Screening Térmico}

A análise de variância demonstrou haver diferença significativa, entre as temperaturas testadas para todas as variáveis analisadas. Na figura 1 , verifica-se que este demonstra uma tendência linear decrescente entre as temperaturas testadas na germinação de Myracrodruon urundeuva.

Verificou-se que a faixa de temperatura entre 20 e $30{ }^{\circ} \mathrm{C}$ mostrou-se bastante favorável à germinação das sementes. No entanto, apesar da porcentagem de germinação das sementes submetidas a $20^{\circ} \mathrm{C}$ ter sido um pouco maior que a $25^{\circ} \mathrm{C}$, esta, então, foi considerada como ótima e mais favorável para a germinação das sementes, uma vez que nesta temperatura, as sementes apresentaram menor tempo médio de germinação e maior valor de IVG e CUG. A temperatura de $33{ }^{\circ} \mathrm{C}$ foi estabelecida como T50, por apresentar germinabilidade próxima de $50 \%$. É importante destacar que, nas temperaturas de 33 e $35^{\circ} \mathrm{C}$, apesar do tempo médio de germinação, da velocidade média e o CUG terem apresentado valores próximos aos obtidos para as mesmas medidas nas temperaturas de 25 e $30{ }^{\circ} \mathrm{C}$, verificou-se que os valores de IVG (Tabela 1 ) foram inferiores, pois estas medidas são dependentes do número total de sementes germinadas, o que nessas temperaturas foram baixas.

Pacheco et al. (2006), estudando o efeito de

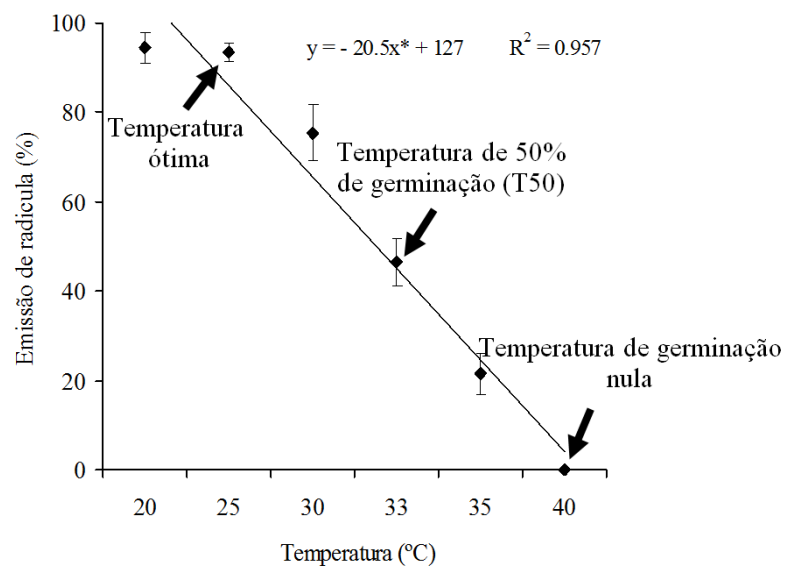

FIGURA 1: Germinabilidade (emissão de radícula) das sementes de Myracrodruon urundeuva nas diferentes temperaturas testadas $\left(20,25,30,33,35\right.$ e $\left.40{ }^{\circ} \mathrm{C}\right)$.

FIGURE 1: Germination (radicle emission) of Myracrodruon urundeuva seeds at different temperatures $(20,25,30,33$, 35 e $\left.40^{\circ} \mathrm{C}\right)$. 
TABELA 1: Medidas de germinação de sementes de Myracrodruon urundeuva submetida a diferentes temperaturas $\left(20,25,30,33,35\right.$ e $\left.40^{\circ} \mathrm{C}\right)$.

TABLE 1: Germination of Myracrodruon urundeuva seeds subjected to different temperatures (20, 25, $30,33,35$ e $\left.40{ }^{\circ} \mathrm{C}\right)$.

\begin{tabular}{ccccccc}
\hline $\begin{array}{c}\text { Temperatura } \\
\left({ }^{\circ} \mathrm{C}\right)\end{array}$ & $\mathrm{n}_{\mathrm{i}}$ & $\begin{array}{c}\mathrm{G} \\
(\%)\end{array}$ & $\begin{array}{c}\mathrm{Tm} \\
(\text { dias })\end{array}$ & $\begin{array}{c}\text { Vm } \\
(\text { dias }-1)\end{array}$ & $\begin{array}{c}\text { IVG } \\
(\text { sem. dia }-1)\end{array}$ & $\begin{array}{c}\text { CUG } \\
(\text { dias }-2)\end{array}$ \\
\hline 20 & 189 & 95 & 2,590 & 0,392 & 19,792 & 2.063 \\
25 & 187 & 94 & 2,212 & 0,453 & 23,238 & 2.575 \\
30 & 151 & 76 & 2,399 & 0,418 & 17,583 & 2.115 \\
33 & 93 & 47 & 2,272 & 0,444 & 11,454 & 2.363 \\
35 & 43 & 22 & 2,713 & 0,410 & 5,570 & 1.426 \\
40 & 00 & 0 & ---- & ---- & ---- & --- \\
\hline $\mathrm{CV}(\%)^{1}$ & & $9.02^{*}$ & $8.76^{*}$ & $3.70^{*}$ & $9.07^{*}$ & $17.99^{*}$ \\
\hline
\end{tabular}

Em que: $\mathrm{n}_{\mathrm{i}}=$ número de sementes germinadas (emissão de radícula); $\mathrm{G}=$ Dados médios de germinabilidade; $\mathrm{Tm}=$ Tempo médio de germinação; Vm = Velocidade média de germinação; IVG = Índice de Velocidade de Germinação; CUG $=$ Coeficiente de uniformidade de germinação; $*$ = significativo a $5 \%$; ns = não significativo para o teste $\mathrm{F}$ da análise da variância (ANOVA); ${ }^{1}=$ Coeficiente de variação para os dados transformados em raiz quadrada de $\mathrm{Y}+0.5$.

temperaturaesubstratoem Myracrodruonurundeuva, encontraram as maiores taxas de germinação (variando entre 79 e $93 \%$ ) para as temperaturas constantes de 25 e $27{ }^{\circ} \mathrm{C}$, respectivamente, em todos os substratos testados. Silva et al. (2002), avaliando uma faixa de temperatura entre $15 \mathrm{e} 35^{\circ} \mathrm{C}$, napresençaenaausênciadeluz, verificaram que as sementes de Myracrodruon urundeuva apresentaram as maiores germinabilidades entre 20 e $30{ }^{\circ} \mathrm{C}$, confirmando assim os dados encontrados no presente estudo. A mesma faixa de temperatura foi encontrada por Silva et al. (2001), para a espécie Schinus terebenthifolius, outra espécie de aroeira. Lucio et al. (2006), trabalhando também com sementes de Myracrodruon urundeuva verificaram que a temperatura de $20{ }^{\circ} \mathrm{C}$ foi mais favorável à germinação de aroeira $(94 \%)$, bem como foi a que propiciou maior IVG, quando comparados aos resultados sob a temperatura de $25{ }^{\circ} \mathrm{C}(89 \%)$. A diferença fisiológica em cada lote de sementes pode justificar as diferenças nos resultados obtidos neste trabalho, sendo registrada uma amplitude de temperatura variando entre 20 a $30^{\circ} \mathrm{C}$ em que a germinação pode estar ocorrendo. A faixa de temperatura entre 20 e $30{ }^{\circ} \mathrm{C}$ tem sido indicada para a germinação de inúmeras espécies florestais (BORGES e RENA 1993), entretanto, a temperatura ótima de germinação de sementes está diretamente associada à característica ecológica da espécie (PROBERT, 2000).

O tempo médio de germinação constitui um parâmetro importante para se avaliar a rapidez de ocupação de uma espécie em uma comunidade (FERREIRA et al., 2001). Neste estudo verificouse que com o aumento da temperatura houve um aumento no tempo médio para iniciar o processo de germinação das sementes de aroeira (Tabela 1). Nas temperaturas de 20,25 e $30^{\circ} \mathrm{C}$ o pico de germinação se deu em torno do $2^{\circ}$ dia após a semeadura, sendo o menor tempo registrado para as sementes semeadas a $25{ }^{\circ} \mathrm{C}$. Verifica-se assim que os diásporos de Myracrodruon urundeuva, em temperaturas ótimas, apresentam alta porcentagem de germinação, superior a $60 \%$, em tempo relativamente curto, em torno de 2 a 3 dias, podendose desta forma, enquadrar a aroeira-do-sertão entre as espécies lenhosas pioneiras, permitindo a esta a rápida exploração das condições favoráveis para a germinação no ambiente. Esses resultados também foram confirmados por outros autores (PACHECO et al., 2006; FIGUEIRÔA, 2004; TEÓFILO et al., 2004).

Não houve emergência de raiz primária na temperatura de $40{ }^{\circ} \mathrm{C}$, sendo assim, em função da taxa nula de germinação, nenhum parâmetro foi avaliado. Este resultado também foi encontrado por Silva et al. (2002), para a mesma espécie. Borges e Rena (1993) afirmam que temperaturas extremas marcam o limite de ocorrência da germinação, sendo que acima do limite superior e abaixo do limite inferior pode ocorrer a morte das sementes. Acredita-se que este fenômeno possa ter ocorrido 
em sementes de Myracrodruon urundeuva, pois ao final dos dias de avaliação do experimento as sementes encubadas a $40{ }^{\circ} \mathrm{C}$, apresentavam-se escurecidas e fungadas. Mesmo após terem sido lavadas e transferidas para sua temperatura ótima de germinação $\left(25^{\circ} \mathrm{C}\right)$, as sementes não germinaram, inferindo-se assim que a perda da viabilidade tenha se dado por morte do embrião.

\section{Screening Hídrico}

Houve efeito significativo $(\mathrm{p}<0,05)$ entre os potenciais osmóticos testados para todas as variáveis analisadas nos dois ensaios. Na Figura 2 observa-se a tendência quadrática decrescente para os dados de germinabilidade, nos quais apresentam um declínio da germinação à medida que o potencial osmótico tornou-se mais negativo.

De modo geral as maiores taxas de germinação foram verificadas nos potenciais: zero, $-0,2$ e $-0,4 \mathrm{MPa}$. A partir do potencial $-0,6 \mathrm{MPa}$ houve uma redução maior na germinabilidade e nos potenciais osmóticos inferiores a $-0,8 \mathrm{MPa}$ ocorreu redução acentuada até sua nulidade. A partir dos

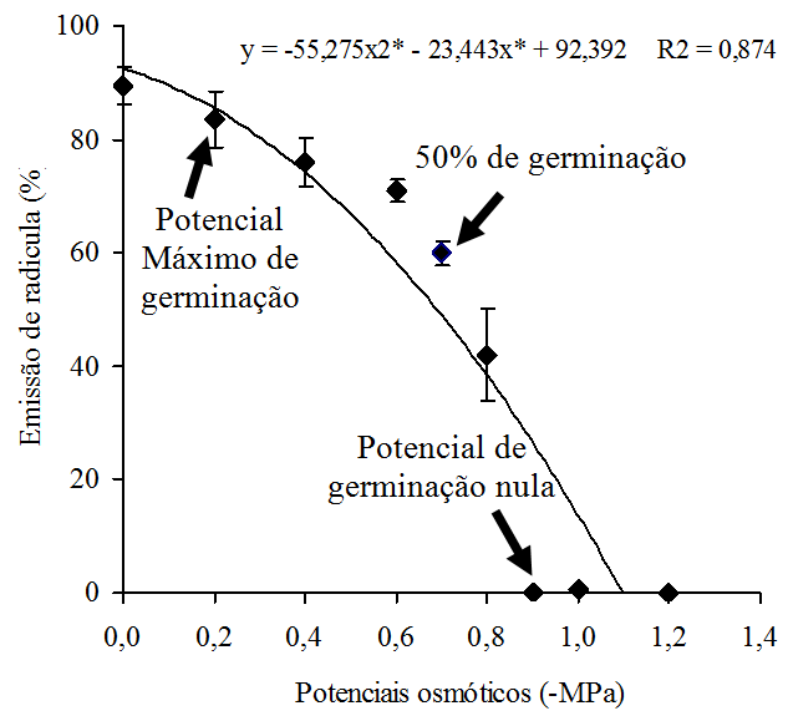

FIGURA 2: Médias de germinação (emissão de radícula) em sementes de Myracrodruon urundeuva submetidas a diferentes potenciais osmóticos $(0,0$; $-0,2 ;-0,4 ;-0,6 ;-0,7 ;-0,8 ;-0,9 ;-1,0$ e $-1,2 \mathrm{MPa})$.

FIGURE 2: Means of germination (radicle emission) in Myracrodruon urundeuva seeds under different osmotic potentials $(0,0 ;-0,2 ;-0,4 ;-0,6 ;-0,7 ;-0,8 ;-0,9$; $-1,0$ e $-1,2 \mathrm{MPa})$. potenciais testados e com referência no tratamento controle $(\mathrm{PO}=0,0 \mathrm{MPa})$, foi possível estabelecer o potencial osmótico de $-0,2 \mathrm{MPa}$ como o potencial máximo de germinação $(84 \%),-0,7 \mathrm{MPa}$ o potencial médio de germinação $(60 \%)$ e a partir de $-0,9 \mathrm{MPa}$ o potencial de estresse $(0 \%)$.

Carvalho et al. (2007) encontraram resultados semelhantes para a mesma espécie. $\mathrm{Na}$ germinação de sementes de catingueira (Caesalpinia pyramidalis), espécie nativa da caatinga, Antunes (2008) registrou a manutenção da capacidade germinativa das sementes nos maiores potenciais osmóticos $(-0,2,-0,4,-0,6 \mathrm{MPa})$ e em níveis altos (88; 90 e 87,33 \% respectivamente). Ribeiro (2008) estudando a germinação de sementes de gliricídia (Gliricidia sepium), espécie também ocorrente no semiárido nordestino, verificou que em potenciais inferiores a -1,0 MPa, a geminação das sementes foi significativamente reduzida, chegando à taxa nula a -1,4 MPa. Sefora (2008), também estudando Gliricidia sepium, verificou que a porcentagem de germinação foi reduzida pela metade quando o potencial osmótico baixou de $0,0 \mathrm{MPa}$ para - $0,5 \mathrm{MPa}$, chegando a valores nulos no potencial osmótico de -2,0 MPa. Já Silva et al. (2005), estudando o efeito do estresse hídrico sobre a germinação de sementes de faveleira (Cnidoscolus juercifolius), uma espécie endêmica do semiárido nordestino, verificaram a inibição completa da germinação a partir de $-0,9$ MPa.

Conforme o potencial osmótico da solução foi reduzido, tanto a germinabilidade foi reduzida como também a velocidade média $(\mathrm{Vm})$, o índice de velocidade de germinação (IVG) e o coeficiente de uniformidade (CUG). Já o tempo médio de germinação (Tm) aumentou, demonstrando que a restrição hídrica, fisiologicamente promoveu um atraso na expansão e divisão das células, e, consequentemente, na emissão da raiz, levando assim mais tempo para as sementes germinarem (Tabela 2).

Com relação ao IVG, vale ressaltar que sendo este influenciado pelo número total de sementes que germinam nas condições do ensaio, seu valor se torna mais significativo para comparações somente quando as amostras ou os tratamentos apresentarem o mesmo número de sementes germinadas (SANTANA e RANAL, 2004). Assim, se avaliarmos o índice com relação a todos os tratamentos testados, observa-se a tendência deste em diminuir, em função da redução da germinabilidade nos diferentes potenciais testados. 
TABELA 2: Medidas de germinação de sementes de Myracrodruon urundeuva submetidas a diferentes potenciais osmóticos durante 9 dias de avaliação.

TABLE 2: Germination of Myracrodruon urundeuva seeds subjected to different osmotic potentials during 9 days of evaluation.

\begin{tabular}{ccccccc}
\hline $\begin{array}{c}\mathrm{PO} \\
(\mathrm{MPa})\end{array}$ & $\mathrm{n}_{\mathrm{i}}$ & $\begin{array}{c}\mathrm{G} \\
(\%)\end{array}$ & $\begin{array}{c}\mathrm{Tm} \\
(\mathrm{dias})\end{array}$ & $\begin{array}{c}\text { Vm } \\
\left(\text { dias }^{-1}\right)\end{array}$ & $\begin{array}{c}\text { IVG } \\
\left(\text { sem. dia }^{-1}\right)\end{array}$ & $\begin{array}{c}\text { CUG } \\
\left(\text { dias }^{-2}\right)\end{array}$ \\
\hline 0,0 & 179 & 90 & 2,112 & 0,474 & 21,708 & 11.992 \\
$-0,2$ & 167 & 84 & 2,670 & 0,375 & 16,740 & 2.018 \\
$-0,4$ & 152 & 76 & 3,205 & 0,313 & 12,830 & 1.418 \\
$-0,6$ & 142 & 71 & 4,813 & 0,209 & 8,108 & 0.466 \\
$-0,7$ & 120 & 60 & 5,103 & 0,196 & 6,317 & 0.518 \\
$-0,8$ & 84 & 42 & 7,319 & 0,137 & 3,050 & 0.567 \\
$-0,9$ & 00 & 00 & ---- & ---- & --- & ---- \\
$-1,0$ & 01 & 01 & ---- & ---- & ---- & ---- \\
$-1,2$ & 00 & 00 & ---- & ---- & ---- & --- \\
\hline $\mathrm{CV}(\%)^{1}$ & & $9.87 *$ & $2.63^{*}$ & $0.80^{*}$ & $7.80^{*}$ & $33.16^{*}$ \\
\hline
\end{tabular}

Em que: $\mathrm{n}_{\mathrm{i}}=$ número de sementes germinadas (emissão de radícula); $\mathrm{G}=$ Dados médios de germinabilidade; $\mathrm{Tm}=$ Tempo médio de germinação; Vm = Velocidade média de germinação; IVG = Índice de Velocidade de Germinação; $\mathrm{CUG}=$ Coeficiente de uniformidade de germinação; $*$ = significativo a $5 \%$; ns = não significativo para o teste $\mathrm{F}$ da análise da variância (ANOVA); ${ }^{1}=$ Coeficiente de variação para os dados transformados em raiz quadrada de y +0.5 .

Avaliando-se a mesma variável nos potenciais 0,0 e $-0,2 \mathrm{MPa}$, assim como nos potenciais $-0,4 \mathrm{e}$ $-0,6 \mathrm{MPa}$, é possível observar o reflexo do IVG na velocidade da germinação em função do tratamento aplicado. Verifica-se que, apesar de as sementes apresentarem uma germinabilidade alta e com valores semelhantes, os resultados de IVG obtidos no potencial de $-0,0 \mathrm{MPa}$ apresentaram-se maiores que o do potencial $-0,2 \mathrm{MPa}$, assim como no potencial de -0,4 MPa e -0,6 MPa. Esses resultados podem ser associados ao efeito da restrição hídrica provocando um retardo no inicio do processo germinativo.

A partir da análise do conjunto de variáveis, é possível verificar que com o aumento do estresse hídrico, as sementes germinaram, porém, o processo ocorreu mais lentamente. Em condições naturais, esse aumento do tempo poderia estar atuando de forma positiva no estabelecimento das plântulas, pois desta forma a germinação das sementes que permanecem viáveis pode ser distribuída no tempo e no espaço, aumentando a probabilidade das plântulas encontrarem condições ambientais adequadas para seu crescimento e desenvolvimento (BEWLEY e BLACK, 1994), caso elas consigam se manter no sistema. Esses dados demonstram que na germinação de sementes de Myracrodruon urundeuva, uma restrição hídrica moderada permite que as sementes completem o processo germinativo de maneira eficiente, porém, num maior espaço de tempo. Por outro lado, em condições de deficiência hídrica mais elevada, como verificado nos potenciais de $-0,7$ a $-0,8 \mathrm{MPa}$, as sementes levaram muito mais tempo para germinar ou evitaram a germinação, como verificado a partir do potencial de $-0,9 \mathrm{MPa}$. Os resultados deste trabalho corroboram com os obtidos por Fonseca e Perez (2003) que verificaram maior tempo requerido para a germinação quando o potencial osmótico foi reduzido da testemunha até $-0,5 \mathrm{MPa}$, para a espécie olho-de-dragão (Adenanthera pavonina). O mesmo foi verificado para as espécies sucupira (Bowdichia virgilioides), canafístula (Peltophorum dubium), fedegoso (Senna occidentalis) e paineira (Chorisia speciosa) (SILVA et al., 2001; PEREZ et al., 2001; DELACHIAVE e PINHO, 2003; FANTI e PEREZ, 2003).

Ao analisar fisiologicamente os dados, estes estão de acordo com Santos et al. (1992), quando afirmam que a embebição depende do gradiente hídrico existente entre a semente e o meio externo; sendo assim, se o potencial osmótico da solução for mais negativo do que aquele apresentado pelas células do embrião, esta dificultará a absorção da água necessária para a germinação de semente. Para Bewley e Black (1994) a inibição na emergência da raiz principal decorrente de uma disponibilidade menor de água relaciona-se frequentemente a 
reduções na atividade de algumas enzimas, com prejuízo ao metabolismo geral das sementes. Analisando-se ecologicamente esse comportamento, em se tratando de espécies de caatinga, é provável que, sob condições hídricas muito desfavoráveis, as sementes evitem a germinação como estratégia de sobrevivência, a fim de garantir o estabelecimento das futuras plântulas (BEWLEY e BLACK, 1982; FERREIRA e BORGHETTI, 2004).

\section{Combinação dos Fatores Abióticos (Térmico x Hídrico)}

As análises de variância para os dois ensaios demonstraram diferença significativa $(\mathrm{p}<0,05)$ para todas as variáveis analisadas. No Ensaio 1 (Tabela 3 ), onde foi combinada a temperatura de $33{ }^{\circ} \mathrm{C}$ (T50) com os potenciais osmóticos 0,$0 ;-0,2 ;-0,7$ e -1,0 MPa, pode-se verificar que só germinaram as sementes do tratamento $-0,2 \mathrm{MPa} / 33^{\circ} \mathrm{C}$, porém, apresentando uma germinabilidade muito baixa (apenas $12 \%$ ). Avaliando-se os dados de formação de plântulas pode-se destacar que os valores obtidos nos tratamento $0,0 \mathrm{MPa} / 33{ }^{\circ} \mathrm{C}$, onde, dos $40 \%$ das sementes que emitiram raiz, apenas $17 \%$ se tornaram plântulas normais, $21 \%$ anormais deterioradas e os $2 \%$ restante morreram.

No Ensaio 2 (Tabela 4), onde foram combinados os potenciais hídricos de $-0,7 \mathrm{MPa}$ ( $\psi 50)$ com as temperaturas de $25{ }^{\circ} \mathrm{C}$ (ótima), de $33{ }^{\circ} \mathrm{C}(\mathrm{T} 50)$ e a máxima de germinação $\left(40{ }^{\circ} \mathrm{C}\right)$, verificou-se que somente no tratamento controle $\left(0,0 \mathrm{MPa} / 33{ }^{\circ} \mathrm{C}\right)$ houve as maiores taxas de germinabilidade das sementes, demonstrando também, neste ensaio, que a combinação dos fatores influenciou negativamente no processo germinativo das sementes de aroeira.

Os resultados obtidos nos dois ensaios indicam que alta temperatura e diminuição dos

TABELA 3: Dados médios de porcentagem de sementes com emissão de radícula, germinação de plântulas normais, anormais e de sementes não germinadas de Myracrodruon urundeuva submetidas à combinação de fatores abióticos durante o teste de germinação. Temperatura de $33{ }^{\circ} \mathrm{C}$ (T50) com os potenciais osmóticos 0,$0 ;-0,2 ;-0,7$ e -1,0 MPa (Ensaio 1).

TABLE 3: Mean data of percentage of seeds with radicle emission, normal seedling, abnormal and nongerminated seeds of Myracrodruon urundeuva submitted to the combination of abiotic factors germination test. Temperature of $33{ }^{\circ} \mathrm{C}$ (T50) with osmotic potentials 0,$0 ;-0,2 ;-0,7$ and $-1,0 \mathrm{MPa}$ (Test 1).

\begin{tabular}{rcccc}
\hline \multirow{2}{*}{ Tratamentos } & $\begin{array}{c}\text { Emissão de radícula } \\
(\%)\end{array}$ & \multicolumn{2}{c}{ Plântulas (\%) } & \multirow{2}{*}{$\begin{array}{c}\text { Sementes não } \\
\text { germinadas (\%) }\end{array}$} \\
\cline { 3 - 4 } & 40 & normais & anormais & \\
\hline $0,0 / 33^{\circ} \mathrm{C}$ & 12 & 17 & 21 & 60 \\
$-0,2 / 33^{\circ} \mathrm{C}$ & 0 & 4 & 9 & 88 \\
$-0,7 / 33^{\circ} \mathrm{C}$ & 0 & 0 & 0 & 100 \\
$-1,0 / 33^{\circ} \mathrm{C}$ & 0 & 0 & 100 \\
\hline
\end{tabular}

TABELA 4: Dados médios de porcentagem de sementes com emissão de radícula, germinação de plântulas normais, anormais e de sementes não germinadas de Myracrodruon urundeuva submetidas à combinação de fatores abióticos durante teste de germinação. Potenciais de $-0,7 \mathrm{MPa}(\psi 50)$ com as temperaturas de $25^{\circ} \mathrm{C}, 33^{\circ} \mathrm{C}$ e $40^{\circ} \mathrm{C}$ (Ensaio 2).

TABLE 4: Mean data of percentage of seeds with radicle emission, normal seedling, abnormal and nongerminated seeds of Myracrodruon urundeuva submitted to the combination of abiotic factors during the germination test potentials of $-0,7 \mathrm{MPa}$ (Y50) with temperatures of $25^{\circ} \mathrm{C}$, $33{ }^{\circ} \mathrm{C}$ and $40{ }^{\circ} \mathrm{C}$ (test 2 ).

\begin{tabular}{ccccc}
\hline \multirow{2}{*}{ Tratamentos } & $\begin{array}{c}\text { Emissão de radícula } \\
(\%)\end{array}$ & \multicolumn{2}{c}{ Plântulas (\%) } & \multirow{2}{*}{$\begin{array}{c}\text { Sementes não } \\
\text { germinadas (\%) }\end{array}$} \\
\cline { 3 - 4 } & 01 & 00 & 00 & 99 \\
$-0,7 / 25^{\circ} \mathrm{C}$ & 00 & 00 & 00 & 100 \\
$-0,7 / 33^{\circ} \mathrm{C}$ & 00 & 00 & 00 & 100 \\
$-0,7 / 40^{\circ} \mathrm{C}$ & & & anormais & \\
\hline
\end{tabular}

Ci. Fl., v. 22, n. 4, out.-dez., 2012 
potenciais osmóticos reduzem a germinabilidade e o vigor das sementes e que estas não toleram o estresse combinado nas fases iniciais do seu desenvolvimento. Poucos estudos têm sido desenvolvidos para investigar o efeito da combinação de fatores abióticos na germinação de sementes, porém, os dados obtidos neste trabalho corroboram com Souza et al. (2008), que, estudando o efeito da interação de estresses abióticos (hídrico x térmico) sobre a germinação de Physalis angulata, comprovaram que a combinação dos fatores em níveis estressantes para a espécie influenciou negativamente a germinação. $\mathrm{O}$ mesmo foi verificado por Ribeiro et al. (2008) em sementes de espécies ocorrentes na caatinga sob efeito de estresse combinado (seca x calor) e Antunes et al. (2008) em sementes de catingueira (Caesalpinia pyramidalis Tul.).

\section{Viabilidade das Sementes Pós-Estresse}

Os dados referentes à avaliação das sementes germinadas em água após condicionamento osmótico estão expressos através das medidas de germinação calculadas apresentadas na Tabela 5, onde é possível verificar que as sementes que estiveram em contato com as soluções osmóticas durante nove dias e em seguida lavadas e transferidas para água, mostraram estar viáveis, e germinaram numa maior velocidade (menor tempo médio) quando comparadas com as sementes mantidas em 0,0 MPa (Tabela 2). As maiores porcentagens de germinação, assim como o IVG, foram registradas para as sementes condicionadas inicialmente nos potenciais mais negativos. Os dados demonstram que a capacidade germinativa das sementes foi mantida após exposição à restrição hídrica induzida. Por esta razão, estes potenciais osmóticos, podem ser sugeridos como potenciais adequados para futuros ensaios de osmocondicionamento para esta espécie.
Virgens et al. (2008), verificaram que sementes de Myracrodruon urundeuva, submetidas a -1,0 $\mathrm{MPa}$, após transferência para água apresentaram $85 \%$ de germinação, sugerindo este potencial para o pré-condicionamento de sementes desta espécie. Borges et al. (2002) estudando o osmocondicionamento em sementes de tamboril-damata (Platymiscium pubescens), espécie florestal de ocorrência no cerrado, quando mantidas em solução -0,4 MPa de PEG 6000 por 120 horas, tiveram $66 \%$ de germinação quando transferidas para água.

Apesar de as sementes terem apresentado capacidade germinativa após o condicionamento osmótico, este só se deu na faixa de $50 \%$, diferente do que foi encontrado por Virgens et al. (2008) para a mesma espécie. Esse resultado pode ter sido influenciado pelo tempo de exposição das sementes à solução osmótica, assim como se deve considerar também a possibilidade de perda da viabilidade do lote, do grau de maturidade das sementes ou até mesmo da imposição de uma dormência secundária. Estudos mais aprofundados necessitam ser feitos para possibilitar uma análise mais conclusiva com relação a esses aspectos.

Sabe-se que, sob condicionamento osmótico, os eventos do processo de germinação são iniciados mesmo em limitada disponibilidade de água para a semente, voltando a ocorrer em condições favoráveis. Isto explica o que foi verificado a partir do experimento conduzido, onde a germinação das sementes em água após o condicionamento osmótico ocorreu em função do fenômeno descrito na literatura, em que as sementes mesmo quando submetidas a potenciais osmóticos negativos tornamse fisiologicamente ativas, mobilizam reservas e iniciam seu processo germinativo sem atingir a fase de alongamento celular, mesmo após alguns dias de contato com a solução osmótica. Isto ocorre porque

TABELA 5: Medidas de germinação de sementes de Myracrodruon urundeuva em água, após condicionamento osmótico (Ensaio 2).

TABLE 5: Germination of Myracrodruon urundeuva seeds in water after priming (test 2).

\begin{tabular}{cccccccc}
\hline $\begin{array}{c}\mathrm{PO} \\
(\mathrm{MPa})\end{array}$ & $\mathrm{n}_{\mathrm{t}}$ & $\mathrm{n}_{\mathrm{i}}$ & $\begin{array}{c}\mathrm{G} \\
(\%)\end{array}$ & $\begin{array}{c}\text { Tm } \\
(\text { dias })\end{array}$ & $\begin{array}{c}\text { Vm } \\
\left(\text { dias }^{-1}\right)\end{array}$ & $\begin{array}{c}\text { IVG } \\
\left(\text { sem. dia }^{-1}\right)\end{array}$ & $\begin{array}{c}\text { CUG } \\
\left(\text { dias }^{-2}\right)\end{array}$ \\
\hline$-0,9$ & 200 & 108 & 54 & 1,627 & 0,615 & 19,229 & 2.621 \\
$-1,0$ & 200 & 95 & 48 & 1,428 & 0,702 & 19,125 & 3.139 \\
$-1,2$ & 200 & 114 & 58 & 1,527 & 0,672 & 22,446 & 1.733 \\
\hline
\end{tabular}

Em que: $\mathrm{n}_{\mathrm{t}}$ : = número de sementes transferidas; $\mathrm{n}_{\mathrm{i}}=$ número de sementes germinadas (emissão de radícula); $\mathrm{G}=$ Dados médios de germinabilidade; $\mathrm{Tm}=$ Tempo médio de germinação; $\mathrm{Vm}=$ Velocidade média de germinação; IVG = Índice de Velocidade de Germinação; CUG = Coeficiente de uniformidade de germinação. 
o efeito da embebição das sementes em uma solução osmótica é a hidratação, porém, de forma restrita, limitada, permitindo que alguns eventos metabólicos do processo germinativo aconteçam sem que a germinação seja completada (DE CASTRO et al., 2004a).

Antunes (2008) em estudo sobre o comportamento germinativo de sementes de catingueira (Caesalpinia pyramidalis) sob efeito de estresse hídrico durante armazenamento registrou, que quando as sementes embebidas na solução osmótica de -1,2 MPa (potencial de germinabilidade nula) foram transferidas para a água, também houve excelente recuperação da germinação de sementes recém-coletas $(86 \%)$, e/ou armazenadas por três $(82 \%)$ e seis meses ( $84 \%)$ em condições controladas.

\section{CONCLUSÕES}

As sementes de Myracrodruon urundeuva iniciam a germinação em dois dias.

$\mathrm{Na}$ temperatura de $25{ }^{\circ} \mathrm{C}$ foi obtida a germinação máxima para as sementes da espécie, na de $33{ }^{\circ} \mathrm{C} 50 \%$ das sementes germinaram e na de $40{ }^{\circ} \mathrm{C}$ a germinabilidade foi nula.

Com relação à restrição hídrica induzida, $-0,2 \mathrm{MPa}$ foi o potencial ótimo de germinabilidade, $-0,7 \mathrm{MPa}$ o potencial de $50 \%$ de germinação e a partir de $-0,9 \mathrm{MPa}$ a germinabilidade foi nula.

Os potenciais osmóticos de - 0,$9 ;-1,0$ e - $-1,2$ $\mathrm{MPa}$, podem ser utilizados para condicionamento osmótico de sementes de Myracrodruon urundeuva.

As sementes de Myracrodruon urundeuva não toleram os estresses de altas temperaturas e diminuição dos potenciais osmóticos, concomitantemente, uma vez que reduzem a germinabilidade e o vigor das sementes.

\section{AGRADECIMENTOS}

À Fundação de Amparo à Pesquisa do Estado da Bahia (FAPESB), pela bolsa concedida e ao Conselho Nacional de Pesquisa e Desenvolvimento $(\mathrm{CNPq})$ pelo auxílio financeiro através do projeto: "Projeto Bioprospecção de Plantas Nativas do Semiárido"(CNPq-554839/2006-7)-Programa Rede Nordeste de Biotecnologia - RENORBIO.

\section{REFERÊNCIAS BIBLIOGRÁFICAS}

ANTUNES, C. G. C. Caesalpinia pyramidalis Tul. (Leguminosae-Caesalpinioideae): Longevidade,
Caracterização Fisiológica da Germinação de Sementes e Crescimento Inicial. 2008. 94 f. Dissertação (Mestrado em Botânica). Feira de Santana, Bahia, 2008.

BASKIN, C. C.; BASKIN, J. M. Seeds: ecology, biogeography, and evolution of dormancy and germination. Academic Press. London, 666 p., 1998.

BEWLEY, J. D.; BLACK, M. Physiology and biochemistry of seeds in relation to germination: development, germination and growth. London: Springer, 1982.

BEWLEY, J. D.; BLACK., M. Seeds: Physiology of development and germination. 2nd ed. New York: Plenum Press, 1994. 445 p.

BORGES, E. E. L. et al. Comportamento fisiológico de sementes osmocondicionadas de Platymiscium pubescens (tamboril-da-mata). Revista Árvore, Viçosa, v. 26, n. 5, p. 603-613, 2002.

BORGES, E. E. L.; RENA, A. B. Germinação de sementes. In: AGUIAR, I. B.; PIÑA-RODRIGUES, F. C. M.; FIGLIOLIA, M. B. (Coord.) Sementes florestais tropicais. Brasília: ABRATES, 1993. $350 \mathrm{p}$.

BRADFORD, K. J. Manipulation of seed water relations via osmotic priming to improve germination under stress conditions. HortScience, v. 21, n. 5, p. 1105-1112, 1986.

BRADFORD, K. J. Water relations on seed germination. In: KIGEL, J.; GALILI, G. Seed development and germination. New York: Marcel Dekker, 1995. $853 \mathrm{p}$.

BRASIL. Ministério da Agricultura Pecuária e Abastecimento. Regras para análise de sementes / Ministério da Agricultura, Pecuária e Abastecimento. Secretaria de Defesa Agropecuária. Brasília: Mapa/ ACS, 2009. 399 p.

CALDEIRA, S. F. Conservação, viabilidade e vigor de diásporo e crescimento inicial de mudas de aroeira (Myracrodruon urundeuva Fr. Allem.). 2007. 183 f. Tese (Doutorado em Ciências) Universidade Federal de São Carlos, 2007.

CARON, B. O. et al. Análise de crescimento de plantas de aroeira vermelha no município de JiParaná, RO. Revista da FZVA, Uruguaiana, v. 14, n. 1, p. 1-13, 2007.

CARVALHO, D. M et al. Avaliação do Estresse HídriconaGerminaçãodeSementes de Myracrodruon urundeuva Fr. All. (ANACARDIACEAE). In: CONGRESSO DE ECOLOGIA DO BRASIL,8., 2007, Caxambu. Anais... Caxambu, 2007. 
DE CASTRO, R. D. et al. Desenvolvimento de sementes e conteúdo de água. In: FERREIRA, A. G.; BORGHETTI, F. (Orgs.). Germinação: Do Básico ao Aplicado. Porto Alegre: Artmed. 2004a. p.51-67. DELACHIAVE, M. E. A.; PINHO, S. Z. Germination of Senna occidentalis Link: seed at different osmotic potential levels. Brazilian Archives of Biology and Technology, Botucatu, v. 46, p.163-166, 2003.

DUARTE, E. F. et al. Avaliação da germinação de sementes de aroeira (Myracrodruon urundeuva (Engler) Fr. Allem.) Anacardiaceae, em diferentes substratos, com e sem exo e mesocarpo. In: CONGRESSO DA SOCIEDADE BOTÂNICA DE SÃO PAULO,13., 2000, São Paulo. Anais... São Paulo: USP, 2000.

FANTI, S.C.; PEREZ, S. C. J. G.A. Efeito do estresse hídrico e envelhecimento precoce na viabilidade de sementes osmocondicionadas de paineira (Chorisia speciosa). Pesquisa Agropecuária Brasileira, Brasília, v. 38, p. 537-543, 2003.

FERREIRA, A. G. et al. Germinação de sementes de Asteraceae nativas no Rio Grande do Sul, Brasil.

Acta Botânico Brasileiro. v. 15, n. 2, p. 231-242, 2001.

FERREIRA, A. G.; BORGHETTI, F. Germinação: do básico ao aplicado. Porto Alegre: Artmed, 2004. $323 \mathrm{p}$.

FERREIRA, D. F. Análises estatísticas por meio do Sisvar para Windows versão 4.0. In: REUNIÃO ANUALDAREGIÃOBRASILEIRADASOCIEDADE INTERNACIONAL DE BIOMETRIA, 45., 2000, São Carlos. Anais... São Carlos, USFCar 2000. p. 255-258.

FIGUEIRÔA, J. M. et al. Crescimento de plantas jovens de Myracrodruon urundeuva Allemão (Anacardiaceae) sob diferentes regimes hídricos. Acta Botanica Brasilica, v.18, n. 3, p. 573-580, 2004.

FONSECA, S. C. L.; PEREZ, S. C. J. G. A. Ação do polietileno glicol na germinação de sementes de Adenanthera payonina L. e o uso de poliaminas na atenuação do estresse hídrico sob diferentes temperaturas. Revista Brasileira de Sementes, Brasília, v. 25, n. 1, p.1-6, 2003.

GONZAGA, T. W. C. et al. Crioconservação de sementes de aroeira (Astronium urundeuva Engl.) e baraúna (Schinopsis brasiliensis Engl.). Revista Brasileira de Produtos Agroindustriais, Campina Grande, v. 5, n. 2, p.145-154, 2003.

HENDRICKS, S. B., TAYLORSON, R. B. Variation in germination and amino acid leakage of seeds with temperature related to membrane phase change. Plant Physiology, v. 581, p. 7-11, 1976.

LARCHER, W. Ecofisiologia Vegetal. São Carlos: Rima Artes e Textos, 2000. 531 p.

LUCIO, A. A. et al. Comportamento fisiológico de sementes de aroeira-do-sertão (Myracrodruon urundeuva Fr. All. Anacardiaceae) submetidas a diferentes temperaturas de germinação. In: SEMINÁRIO PANAMERICANO DE SEMENTES, 20., 2006, Fortaleza. Anais... Fortaleza: ABRASEM, 2006.

LUCIO, A. D. C. et al. Relações entre variáveis nas análises de sementes de espécies florestais nativas do Rio Grande do Sul. Ciência Rural, Santa Maria, v. 37, n. 3, p. 697-704, 2007.

MEDEIROS, A. C. S. et al. Comportamento fisiológico de sementes de aroeira (Myracrodruon urundeuva Fr.All.) em condições de armazenamento. Boletim de Pesquisa Florestal, Colombo, n. 40, p. 85-98, 2000.

MICHEL, B. E.; KAUFMANN, M. R. The osmotic potencial of poliethylene glycol 6000 . Plant Physiology, Rockville, v. 51, n. 5, p. 914916, 1973.

MIRANDA, W. O. et al. Influência da luz na germinação de sementes de aroeira (Myracrodruon urundeuva) ocorrentes em dois fragmentos de Floresta Estacional Decidual no norte de Minas Gerais. In: CONGRESSO DE ECOLOGIA DO BRASIL, 8., 2007, Caxambú-MG. Anais... Caxambú, 2007.

PACHECO, M. V. et al. Efeito da temperatura e substratos na germinação de sementes de Myracrodruon urundeuva Fr. All. (Anacardiaceae). Revista Árvore, v. 30, n. 3, p. 359-367, 2006.

PEREZ, S. C. J. G. de A. et al. Influência da luz na germinação de sementes de canafístula submetidas ao estresse hídrico. Bragantia, Campinas, v. 3, n. 60, p. 155-166, 2001.

PROBERT, R. J. The role of temperature in germination ecophysiology. In: FENNER, M. Seed: the ecology of regeneration in plant communities. 2th ed. CAB International, 2000, $392 \mathrm{p}$.

RAVEN, P. H. et al. Biologia vegetal. Rio de Janeiro: Guanabara Koogan, 2001. 906 p.

RIBEIRO, R. C. Efeito do Armazenamento na Viabilidade de Sementes de Gliricidia sepium (Jacq.) Steud. (Leguminosae - Papilionoideae) Introduzida do Semi-Árido Baiano. 2008. Dissertação (Mestrado em Botânica). Feira de Santana, Bahia, 2008.

SANTANA, D. G.; RANAL, M. A. Análise 
estatística na germinação: um enfoque estatístico. Brasília: UnB, 2004, 248 p.

SANTOS, V. L. M. et al. Efeito do estresse salino e hídrico na germinação e vigor de sementes de soja. Revista Brasileira de Sementes, Brasília, v.14, n. 2, p.189-194, 1992.

SÉFORA, G. G. de F. Estresse Osmótico na Germinação, crescimento e nutrição mineral da Gliricidia (Gliricidia sepium Jack. Walp). 2008. 49 f. Dissertação (Mestrado). CSTR UFCG. Patos, 2008.

SILVA, L. M. de M. et al. Efeito da luz e da temperatura na germinação de sementes de aroeira (Myracrodruon urundeuva Allemão). Revista Árvore, v. 26, n. 6, p. 691-697, 2002.

SILVA, L. M. de M. et al. Estresse hídrico e condicionamento osmótico na qualidade fisiológica de sementes de Cnidoscolus juercifolius. Revista Brasileira de Engenharia Agrícola e Ambiental, v. 9, n. 1, p. 66-72, 2005.

SILVA, L. M. de M. et al. Seed germination of Bowdichia virgilioides Kunth, under water stress.

Revista Brasileira de Engenharia Agrícola e Ambiental, Campina Grande, v. 5, p.115-118,
2001.

SOUZA, S. C. A. et al. Conservação de Sementes de Myracodruon urundeuva Freire Allemão (Anacardiaceae) em Diferentes Condições de Armazenamento. Revista Brasileira de Biociências, Porto Alegre, v. 5, p. 1140-1142, 2007. TEÓFILO, E. M. et al. Qualidade fisiológica de sementes de aroeira (Myracrodruon urundeuva) em função do tipo de embalagem, ambiente e tempo de armazenamento. Revista Ciência Agronômica, Fortaleza, v. 35, n. 2, p. 371-376, 2004.

TROVÃO, D. M. B. M. et al. Avaliação do potencial hídrico de espécies de Caatinga sob diferentes níveis de umidade no solo. Revista de Biologia e Ciências da Terra, v. 4, n. 2, 2004.

VILLELA, F. A. et al.. Tabela de potencial osmótico em função da concentração de polietilenoglicol 6.000 e da temperatutra. Pesquisa Agropécuaria Brasileira, v. 26, p. 1957-1968, 1991.

VIRGENS, I. O. et al. Avaliação do comportamento fisiológico de sementes de Myracrodruon urundeuva Fr. All. Submetidas a estresse hídrico. In: CONGRESSO NACIONAL DE BOTÂNICA, 59., 2008, Natal. Anais...Natal, 2008. 